\title{
EXPLORING LAND COVER EFFECTS ON URBAN AIR QUALITY: A CASE OF 659 DISTRICTS IN INDIA
}

\author{
Wangwang $\mathrm{Gao}^{1}$, Linyan $\mathrm{Bai}^{1}$, Jianzhong Feng ${ }^{2}, *$, Dan $\mathrm{Cao}^{1}$, Mengrui $\mathrm{Cui}^{1}, \mathrm{Ziwei}^{1}{ }^{1}$, Chenyang Duan ${ }^{1}$ \\ ${ }^{1}$ Key Laboratory of Digital Earth Science, Institute of Remote Sensing and Digital Earth, Chinese Academy of Sciences, Beijing, \\ China-gww_9527@163.com,baily@aircas.ac.cn,caodan_130923@163.com,(1762017268, 995829916, 970902397)@qq.com \\ ${ }^{2}$ Agricultural Information Institute, Chinese Academy of Agricultural Sciences, Beijing, China, - fengjianzhong@caas.cn
}

\section{Commission III, WG III/8}

KEY WORDS: Land Use and Land Cover Changes (LUCC), Urbanization, Air Quality, Fine Particulate Matter (PM 2.5$)$, Districtlevel, India

\begin{abstract}
:
Land use and land cover changes (LUCC) affects the atmospheric environment directly or indirectly. Therefore, understanding the atmospheric response to LUCC is of great significance to maintain and improve the ecological environment. In this study, based on fine particulate matter $\left(\mathrm{PM}_{2.5}\right)$ and LC products, we first compared the differences of $\mathrm{PM}_{2.5}$ between urban and surrounding areas, and then further investigated the variations of $\mathrm{PM}_{2.5}$ in different and land cover (LC) using Mann-Kendall (MK) test and Sen's trend analysis approach at the district-level in India during 1998-2015. The results showed that the numbers of districts where the differences of $\mathrm{PM}_{2.5}\left(D_{\mathrm{PM}_{2.5}}\right)$ between urban and the surrounding areas were greater than zero were increasing during 1998-2015. There is an upward trendency of annual mean $\mathrm{PM}_{2.5}$. The annual mean $\mathrm{PM}_{2.5}$ was higher than $40 \mu \mathrm{g} / \mathrm{m}^{3}$ in $58 \%$ of India's areas where there were mainly located in the Ganges plains of northern India with cropland (L01) and urban areas (L07). The annual mean PM2.5 was less than $10 \mu \mathrm{g} / \mathrm{m}^{3}$ were mainly found in north-western India with permanent ice and snow (L10), accounting for $10 \%$ of India's area. There are significant positive trends of $\mathrm{PM}_{2.5}$ concentration in $90 \%$ of cropland (L01) and $88 \%$ of urban area (L07) and the average slope were $0.83 \mu \mathrm{g} / \mathrm{m}^{3}$ and $0.82 \mu \mathrm{g} / \mathrm{m}^{3}$ respectively, which were higher than those in the rest of LC. This research serves as the basis of reference for the equitable allocation of land resources and restructuring of land use and land cover patterns in urban areas of India that severely affected by air pollution.
\end{abstract}

\section{INTRODUCTION}

The remarkable conversion of land from natural and agricultural areas into residential and urban have taken place since the rapid development of urbanization. These severe unsustainable use of natural resources over the years may lead to tremendous environment degradation (Justice et al., 2015). Deforestation, grassland degradation, soil desertification, together with other urbanization process impacts, all may reduces the air purification capacity of vegetation around the city. Furthermore, it have a significant positive effect on national fine particulate matter $\left(\mathrm{PM}_{2.5}\right)$ concentrations increase in developing countries (Wang et al., 2019). Therefore, a better understanding of land use and land cover changes (LUCC) and their interactions with the atmospheric environment is essential for the sustainable management of natural resources, environmental protection and air quality, especially for address these LUCC issues that associated with air pollution (Vadrevu et al., 2017).

As the world's most populous nation, more than $34 \%$ of the population of India live in urban areas, and it is projected to reach $52.8 \%$ by 2050 (United Nations, 2019). India has been progressing on a path characterized by rapid urbanization along with population growth. Over recent decades, India has witnessed increasing concentrations of $\mathrm{PM}_{2.5}$ from multiple anthropogenic emissions sources, e.g., vehicles, manufacturing, electricity generation, construction and road dust, waste burning, and household energy use (Kumar et al., 2017; Sharma et al., 2016). Especially, according to global urban ambient air quality database (WHO, 2016), there are 14 of world's 20 most polluted cities in India in terms of $\mathrm{PM}_{2.5}$ levels. Rapid urbanization and population growth especially in the last decade have adversely affected urban climate and air quality of India (Saikawa et al., 2017; Sahu et al., 2017). Shi et al. (2017) founded that India consistently showed the largest $\mathrm{PM}_{2.5}$ concentrations during 1999-2014, which were significantly higher than for any other countries. Han et al. (2015) analyzed $\mathrm{PM}_{2.5}$ concentration varies for different land covers in China based on a single-year LC data. $\mathrm{Li}$ et al. (2018) explored the urban $\mathrm{PM}_{2.5}$ pollution situation for 2014-2016 and investigated the impact of landscape factors on urban $\mathrm{PM}_{2.5}$ in China at the city level. To date, many studies about the impact of changes in land use and land cover on air quality have been undertaken in China. However, only a few studies have investigated $\mathrm{PM}_{2.5}$ concentration variation different land covers with long-term trends and spatial variations in India, where LUCC are also rapidly evolving in the process of urbanization. It is noted that these studies have limited applicability with regard to India, as a result of the large differences between India and the other study areas.

Therefore, based on longer-term LC products, we aimed at quantifying differences compared ( $\mathrm{PM}_{2.5}$ ) concentrations in 659 districts of Indian urban and the surrounding regions during 1998-2015 in this study. Additionally, we explored how $\mathrm{PM}_{2.5}$

\footnotetext{
* Corresponding author
} 
concentration varies for different land covers using MannKendall (MK) test and Sen's trend analysis approach.

\section{MATERIALS AND METHODS}

\subsection{Land Cover}

European space agency (ESA) released a consistent multitemporal global land cover maps at $300 \mathrm{~m}$ spatial resolution covering 1992 to 2015 (https://www.esa-landcovercci.org/?q=node/164), and the detailed calculation process can refer to the Plummer et al. (2017). In this study, it was employed to analyze the difference of $\mathrm{PM}_{2.5}$ in the urban area (urban area LC class) and surrounding regions, and the original LC classes were further reclassified into 10 major LC types: agriculture (L01), forest (L02), mosaic herbaceous cover (L03), shrubland (L04), grassland (L05), sparse vegetation (L06), urban area (L07), bare area (L08), water (L09), and permanent snow and ice (L10).

\section{2 $\mathrm{PM}_{2.5}$ Concentration Differences}

For evaluating the long-term $\mathrm{PM}_{2.5}$ variabilities across India, this study used a satellite-based gridded $\mathrm{PM}_{2.5}$ dataset obtained from the Dalhousie University Atmospheric Composition Analysis Group Work (available at http://fizz.phys.dal.ca/ atmos/martin/?page_id=140). This dataset is compiled using a integrated geophysical-statistical method, which provides a $0.01^{\circ} \times 0.01^{\circ}$ grid at global scale for each year from 1998 to 2016 (van Donkelaar et al., 2016). The accuracy of this dataset is assessed by world-wide groundmeasured $\mathrm{PM}_{2.5}$ records in 2010, and the result presents a consistent agreement with ground-measured $\mathrm{PM}_{2.5}$, with an outof-sample cross-validated $\mathrm{R}^{2}$ value of $0.81(\mathrm{~N}=1855)$. The results indicates that the dataset can be utilized for large-scale $\mathrm{PM}_{2.5}$ related studies. In this research, we applied the dataset from 1998 to 2015 to analyze the long-term spatial variation of $\mathrm{PM}_{2.5}$ concentration in different LC of India. Additionally, the annual air quality standard of World Health Organization's (WHO) was used in this research (WHO, 2006). The standard has four levels: the air quality guideline (AQG; $10 \mu \mathrm{g} / \mathrm{m}^{3}$ ), and three interim targets (IT-1: $35 \mu \mathrm{g} / \mathrm{m}^{3}$; IT-2: $25 \mu \mathrm{g} / \mathrm{m}^{3}$; IT-3: 15 $\left.\mu \mathrm{g} / \mathrm{m}^{3}\right)$. Especially, $40 \mu \mathrm{g} / \mathrm{m}^{3}$ is also set as a reference value to evaluate the serious degree of local air pollution according to National Ambient Air Quality Annual Standards of India (NAAQAS).

To explore the temporal and spatial distribution characteristics of $\mathrm{PM}_{2.5}$ concentrations between urban and the surrounding regions, the $\mathrm{PM}_{2.5}$ concentration differences approach was employed in this study (Han et al., 2014). Firstly, average PM$_{2.5}$ concentrations were calculated at the municipal level using the $\mathrm{PM}_{2.5}$ concentration dataset. The $\mathrm{PM}_{2.5}$ concentration in the urban/nonurban areas (UrbanPM 2.5 /NonUrbanPM ${ }_{2.5}$ ) was then calculated based on the ESA LC dataset. The differences in $\mathrm{PM}_{2.5}$ concentration $\left(D_{\mathrm{PM}_{2.5}}\right)$ between UrbanPM $\mathrm{P}_{2.5}$ and Non UrbanPM 2.5 were obtained with the following equation:

$$
D_{\mathrm{PM}_{2.5}}=\mathrm{UrbanPM}_{2.5}-\text { NonUrbanPM }_{2.5}
$$

\subsection{Trend Analysis Approach}

Mann-Kendall (MK) trend test is a nonparametric test method (Mann., 1945; Kendall., 1948). This method does not require a normal distribution of data, and is an efficient statistical tool for analyzing changes within long-term trends of air pollutant concentration data (Faridi et al., 2018; Bigi et al., 2014). The null hypothesis $\mathrm{H} 0$ is that the data series $x_{k}(k=1,2$, $3 \ldots, n)$ are independent from one another and has the same distribution, and the alternative hypothesis $\mathrm{H} 1$ is that there is a monotonic trend in the data series. The MK trend test is calculated as following:

$$
S=\sum_{i=1}^{n-1} \sum_{i=j+1}^{n} \operatorname{sgn}\left(\mathrm{x}_{j}-\mathrm{x}_{i}\right)
$$

where $\quad x_{j}$ is the sequential data value $n$ is the size of the dataset sgn is calculated as follows:

$$
\operatorname{sgn}\left(\mathrm{x}_{j}-\mathrm{x}_{i}\right)=\left\{\begin{array}{cl}
1 & \text { if } \mathrm{x}_{j}>\mathrm{x}_{i} \\
0 & \text { if } \mathrm{x}_{j}=\mathrm{x}_{i} \\
-1 & \text { if } \mathrm{x}_{j}<\mathrm{x}_{i}
\end{array}\right.
$$

According to Mann (1945) and Kendall (1948), when $n \geq 8$, the test statistics $S$ is approximately normally distributed with the mean and variance as follows:

$$
\begin{gathered}
E(\mathrm{~S})=0 \\
\mathrm{~V}(\mathrm{~S})=\frac{n(\mathrm{n}-1)(2 \mathrm{n}+5)-\sum_{m=1}^{n} t_{m} m(\mathrm{~m}-1)(2 m+5)}{18}
\end{gathered}
$$

where $\quad t_{m}$ is the number of extent $m$

The standardized test statistics $Z$ is calculated using the following formula:

$$
Z=\left\{\begin{array}{cl}
\frac{S-1}{\sqrt{\mathrm{V}(\mathrm{S})}} & S>0 \\
0 & S=0 \\
\frac{S+1}{\sqrt{\mathrm{V}(\mathrm{S})}} & S<0
\end{array}\right.
$$

$|Z \alpha|=1.65$, 1.96, and 2.58, which correspond to the critical values at the significance level $P=0.1,0.05$, and 0.01 , respectively. If $|Z|>|Z \alpha|$, the null hypothesis $\mathrm{H} 0$ is rejected. In our study, annual averages of $\mathrm{PM}_{2.5}$ concentrations were used for the long-term trend analysis. However, MK test indicates only the direction of increasing and decreasing air pollutants. To analyze the magnitude of trends, we used Sen's slope estimator, which is the robust estimator for the amplitude of trend slopes as proposed by Sen (1968):

$$
\text { Slope }=\operatorname{Median}\left(\frac{x_{j}-x_{i}}{j-i}\right) \quad(1 \leq i<j \leq n)
$$

where slope is the monotonic increase or decrease rate, or the linear slope, of the entire data series $x_{k}(k=1,2,3, \ldots, \mathrm{n})$ or any segmentation $x_{w}(w=I, i+1, i+2, \ldots, j)$.

The $\mathrm{PM}_{2.5}$ trend was calculated as the significant $(P<0.05$ in this study) slope of the Mann-Kendall (MK) trend test at each pixel's time series. Positive/negative trends were then defined as trends larger than zero/smaller than zero, respectively. 
Median denotes the function to take the median value, and conductes a significance test on the result of the Sen's trend analysis using the MK approach (Wang et al., 2018).

\section{RESULTS AND DISCUSSION}

\subsection{Spatial Pattern of Average $\mathbf{P M}_{2.5}$ Concentration}

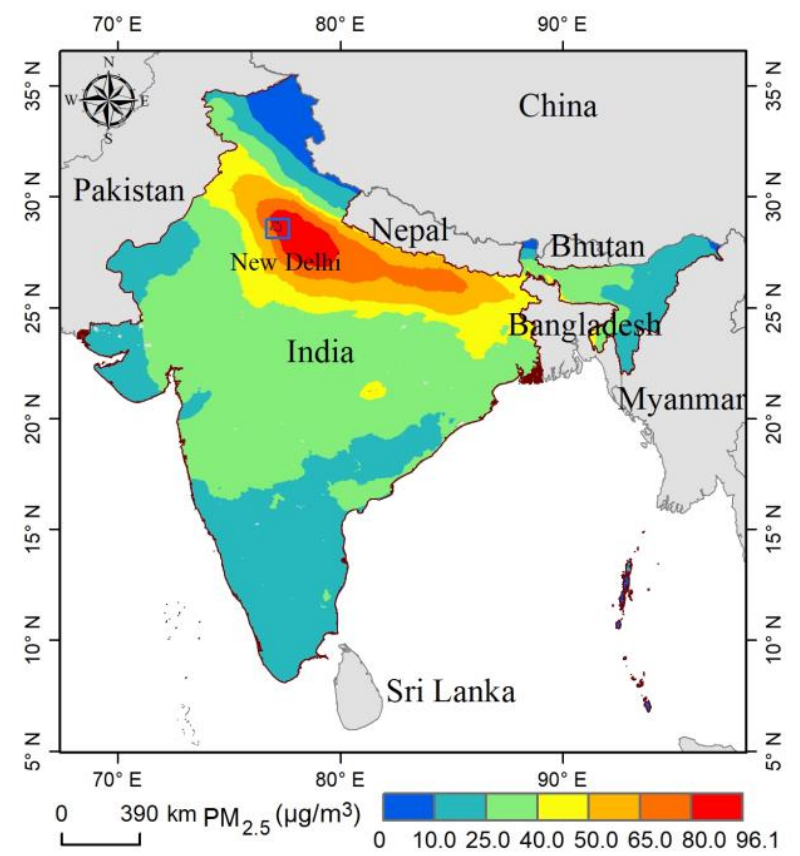

Figure 1. Spatial distribution of average $\mathrm{PM}_{2.5}$ in India during 1998-2015

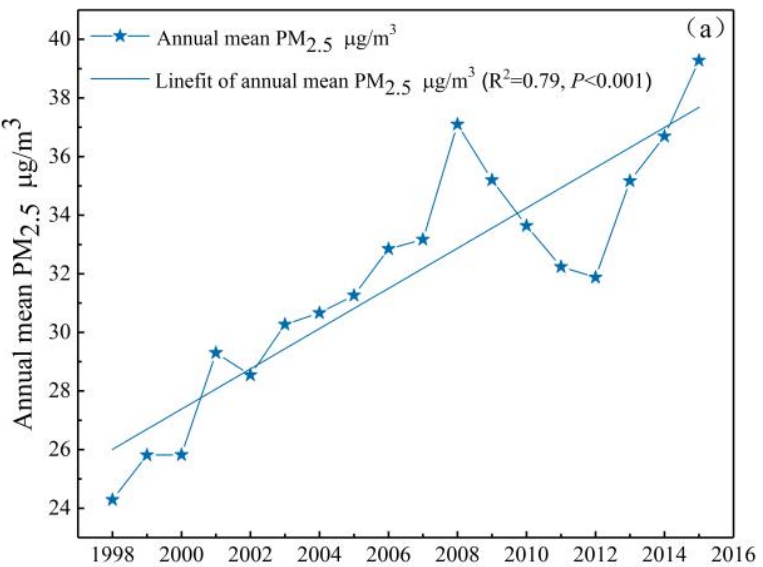

The annual mean of $\mathrm{PM}_{2.5}$ from 1998 to 2015 in India presented an obvious three-stage stepped-down spatial distribution from the Ganges plain to north and south of India. Spatial distribution of each stage was distinctly different (Figure 1). High concentration of $\mathrm{PM}_{2.5}$ was found in Ganges plain, which including the capital city-New Deihi. There are fertile land and excellent geographical conditions in the Ganges plain, which makes many cities with large population located, such as New Delhi, Kanpur and Lucknow. The air pollution caused by traffic exhaust is also one of the pollution sources that can not be ignored (Sharma et al., 2016), which brought great pressure to the local atmospheric environmental quality. In addition, Punjab and Haryana are India's principal agricultural areas, with a large proportion of farming and large-scale straw burning emissions. However, due to the Himalayas blocking, the region is prone to inversion and the overall atmospheric environment is relatively stable (Saikawa et al., 2019). To summarise, a large number of anthropogenic emissions of atmospheric pollutants, coupled with unfavorable conditions for the spread of atmospheric pollutants and the transmission of atmospheric pollutants from adjacent areas (e.g., Punjab, Haryana), which led to the Ganges plain becoming the most polluted area in India.

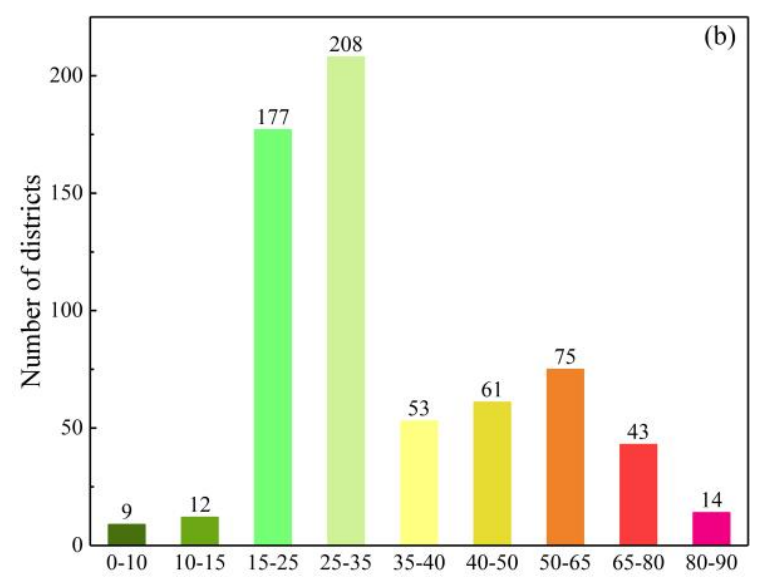

Figure 2. $\mathrm{PM}_{2.5}$ annual mean change (a) and the number of districts different levels of annual mean $\mathrm{PM}_{2.5}$ (b)

Figure 2a showed the annual mean $\mathrm{PM}_{2.5}$ concentration change in India during 1998-2015. Overall, there was an upward trend of annual mean $\mathrm{PM}_{2.5}$ concentration with $\mathrm{R}^{2}=0.79(P<0.001)$ in India. However, the change characteristics were variously in different stages. From 1998 to 2001, the average annual value of $\mathrm{PM}_{2.5}$ showed a rapid upward trend (the average annual average of $\mathrm{PM}_{2.5}$ in 1999-2000 was basically same), and reached a peak in 2001. In 2002, the annual mean $\mathrm{PM}_{2.5}$ showed a brief and significant decline, but then it rebounded and continued to rise, and reached the highest value in 2008 since 1998. After that, the annual mean $\mathrm{PM}_{2.5}$ experienced the longest period of continuous decline in the annual mean $\mathrm{PM}_{2.5}$ in India during 1998-2015, while it dropped to valley value of $32 \mu \mathrm{g} / \mathrm{m}^{3}$ in 2012. After 2012, the annual mean $\mathrm{PM}_{2.5}$ rose sharply and it reached nearly $40 \mu \mathrm{g} / \mathrm{m}^{3}$ in 2015 , which reflected the air quality of India suffering a sharp deterioration tendency during 20122015. According to the number of districts in different annual mean $\mathrm{PM}_{2.5}$ levels (Figure 2b), there are 9 districts with $10 \mu \mathrm{g} / \mathrm{m}^{3}$ meeting the air quality guidelines set by the World Health Organization. The number of districts reaching WHO IT-3 $\left(15 \mu \mathrm{g} / \mathrm{m}^{3}\right)$, IT-2 $\left(25 \mu \mathrm{g} / \mathrm{m}^{3}\right)$ and IT-1 $\left(35 \mu \mathrm{g} / \mathrm{m}^{3}\right)$ is 12,177 and $208,1.82 \%, 26.86 \%$ and $31.56 \%$ of which accounts for the total districts respectively. Especially, $38.39 \%$ of the 659 districts with an annual average $\mathrm{PM}_{2.5}$ were higher than $40 \mu \mathrm{g} / \mathrm{m}^{3}$, indicating that more than one-third of distric had experienced serious air pollution. In addition, there were 14 
districts with an annual mean $\mathrm{PM}_{2.5}$ more than $80 \mu \mathrm{g} / \mathrm{m}^{3}$, which showed that the air quality of those regions were extremely severe.

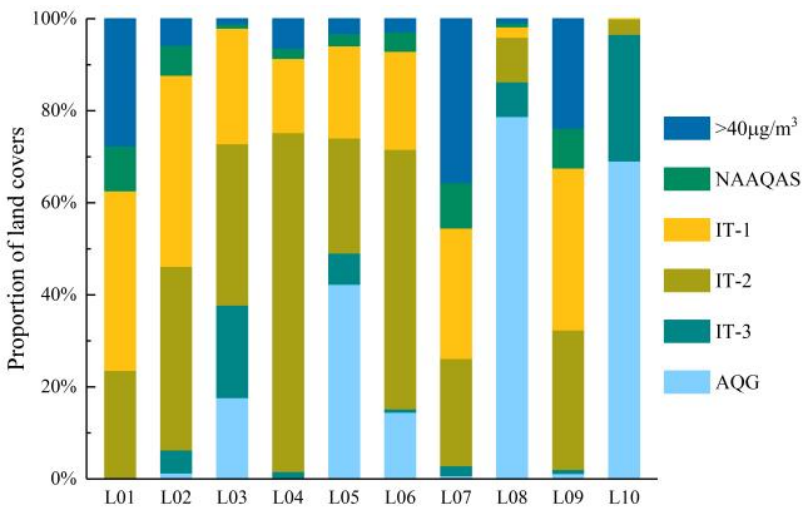

Figure 3. Proportion of $\mathrm{PM}_{2.5}$ at each level in different LC types

In order to further explore the characteristics of $\mathrm{PM}_{2.5}$ in different LC types in India, average PM2.5 from 1998 to 2015 in different LC types were counted respectively (Figure 3). Average $\mathrm{PM}_{2.5}$ were above $40 \mu \mathrm{g} / \mathrm{m}^{3}$ in the areas where the urban area (L07), farmland (L01) and water (L09) were the three largest types. The atmospheric pollutants caused by the mass population living in the urban area and the industrial pollutants caused by industrial production made the air pollution in L07 very severe. Different from $\mathrm{PM}_{2.5}$ in L07 and L09 types which occupied a larger proportion in NAAQAS level, annual average $\mathrm{PM}_{2.5}$ in shrub (L04), herbaceous cover (L03), woodland (L02) and sparse vegetation (L06) accounted for IT-1, IT-2 in most areas, indicating that air quality in these regions was relatively good. However, the air quality in these areas had not yet been optimistic and needed further attention. Grassland (L05), bare (L08) and permanent ice and snow (L10), where there was no obvious emission, were less affected by human activities. The $\mathrm{PM}_{2.5}$ in these regions was below $10 \mu \mathrm{g} / \mathrm{m}^{3}$ (AQG), and indicating that the air quality was the good.

\subsection{Trend of $\mathrm{PM}_{2.5}$ Concentration, 1998-2015}

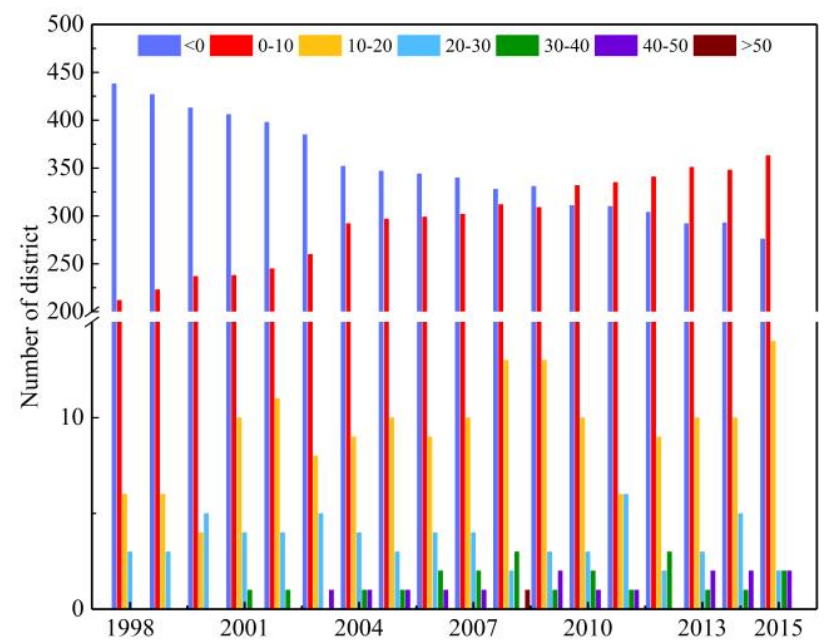

Figure 4. Districts of $D_{\mathrm{PM}_{2.5}}$ in India during 1998-2015
$<0 \mu \mathrm{g} / \mathrm{m}^{3}$ decreased from 438 in 1998 to 276 in 2015, indicating that the air pollution in Indian districts was getting worse. The amount of districts with $D_{\mathrm{PM}_{2.5}}$ between 10 to $20 \mu \mathrm{g} / \mathrm{m}^{3}$ was more than doubled from 6 in 1998 to 14 in 2015. In addition, districts with $D_{\mathrm{PM}_{2.5}}>30 \mu \mathrm{g} / \mathrm{m}^{3}$ emerged continuously, especially in 2003 , it overpassed $40 \mu \mathrm{g} / \mathrm{m}^{3}$, indicating the air quality situation in urban areas had further deteriorated.

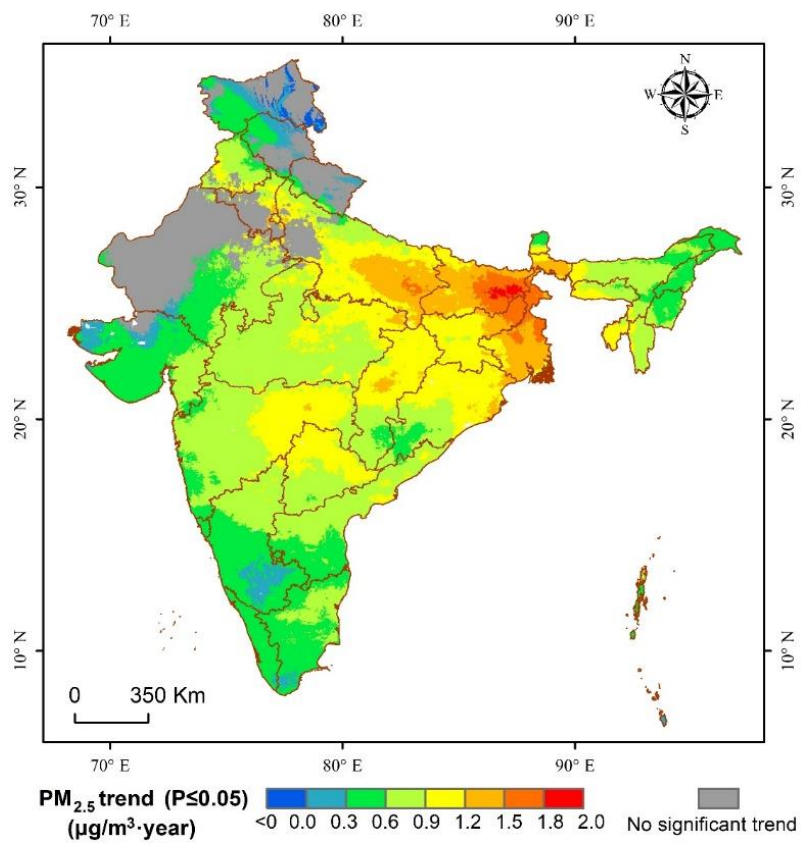

Figure 5. Significant trends of PM2.5 using MK test and Sen's slope in India during 1998 to 2015

The area with strong significant positive trends was obtained mainly in the Ganges plain, northern Chhattisgarh and Jharkhand. In particular, $\mathrm{PM}_{2.5}$ in Patnabang and its adjacent West Bengal region located in the southeastern part of the Ganges River region was increasing at a rate of $1.2 \mu \mathrm{g} / \mathrm{m}^{3}$ or more. While the annual growth trend of $\mathrm{PM}_{2.5}$ in most of southern India (including Tamil Nadu, Kerala, Andhra Pradesh, Goa and Karnataka), and western India (including Gujarat and western Rajasthan) were less than $0.9 \mu \mathrm{g} / \mathrm{m}^{3}$. There was no significant change of $\mathrm{PM}_{2.5}$ in the western Thar Desert and the Himalayas area in the northwest of India, and the $\mathrm{PM}_{2.5}$ even had a significant downward trend in the partial areas of Himalayas. The main LC types in these areas were permanent ice and snow and water, which was likely due to the low intensity of human activities and the low emissions of air pollutants.
Figure 4 showed statistics of $D \mathrm{PM}_{2.5}$ in 659 districts in India. The number of districts with $D_{\mathrm{PM}_{2.5}}>0$ showed a significant increasing trend, especially the number of districts with $D_{\mathrm{PM}_{2.5}}$ between 0 and 10 . However, the amount of districts with $D_{\mathrm{PM}_{2.5}}$ 


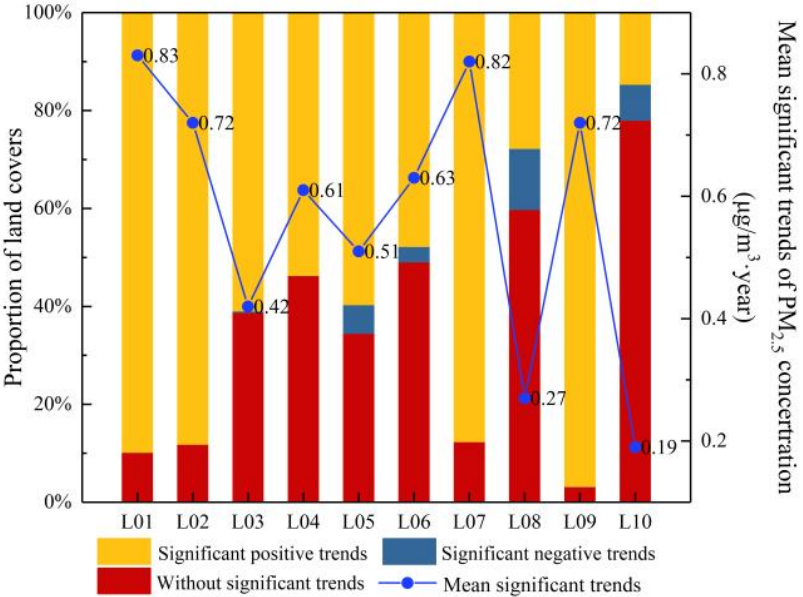

Figure 6. Significant trends of $\mathrm{PM}_{2.5}$ in different LC types during 1998-2015

We can see from the Figure 6 that except for bare area and permanent ice and snow LC types, the other types of $\mathrm{PM}_{2.5}$ had a more proportion significant positive trend than others, indicating that $\mathrm{PM}_{2.5}$ of these types was mainly increasing. The average increase trend of farmland type $\left(0.83 \mu \mathrm{g} / \mathrm{m}^{3}\right)$ was the largest in all LC types, followed by the urban area $\left(0.82 \mu \mathrm{g} / \mathrm{m}^{3}\right)$. The average annual growth rate of $\mathrm{PM}_{2.5}$ in forest and water LC types is stable, but the proportion of significant positive trends in water is obviously higher than that in forest, indicating that the water is suffering from more serious air pollution than forest.

\section{CONCLUSIONS}

In this study, we utilized $\mathrm{PM}_{2.5}$ and LC products from remote sensing first analysed the differences in $\mathrm{PM}_{2.5}$ concentrations between urban and surrounding areas in India, and further investigated the response of $\mathrm{PM}_{2.5}$ to $\mathrm{LC}$ using $\mathrm{MK}$ test and Sen's slope methods during 1998 to 2015. The following conclusions can be drawed:

1) The number of districts with $D_{\mathrm{PM}_{2.5}}>0$, especially those with between 0 and 10, increased continuously during 1998-2015. The number of districts with $D_{\mathrm{PM}_{2.5}}>0$ predominated since 2010 .

2) The most serious $\mathrm{PM}_{2.5}$ pollution areas were located in the northern India, especially Ganges plain. The annual average $\mathrm{PM}_{2.5}$ showed an upward trend from 1998 to 2015. Areas of annual mean $\mathrm{PM}_{2.5}$ higher than NAAQAS were mainly distributed in farmland and urban areas, which accounted for $58 \%$ of India's area. However, there was only $10 \%$ of areas with $\mathrm{PM}_{2.5}<10 \mathrm{ug} / \mathrm{m}^{3}$, and these areas were mainly found in the permanent ice and snow (L10) in northwestern India.

3) $90 \%$ of the cropland and $88 \%$ of the urban area were found significant positive trends and the average trends of $\mathrm{PM}_{2.5}$ in these regions were $0.83 \mathrm{ug} / \mathrm{m}^{3}$ and $0.82 \mathrm{ug} / \mathrm{m}^{3}$ respectively, which were higher than those other land covers.

\section{ACKNOWLEDGEMENTS}

This study was supported by the Strategic Priority Research Program of the Chinese Academy of Sciences (Grant No. XDA19030302), the Key Scientific and Technological Research Projects of Xinjiang Corps (Grant No.2019AB036). The authors would like to thank Dr. van Donkelaar Aaron of the Atmospheric Physics Institute of the Dalhousie University in Canada for offered the remotely sensed $\mathrm{PM}_{2.5}$ No Dust data used in this study. The authors also give thanks to the anonymous reviewers for their careful reading and helpful remarks.

\section{REFERENCES}

Bigi, A., Ghermandi, G., 2014. Long-term trend and variability of atmospheric $\mathrm{PM}_{10}$ concentration in the Po Valley. Atmos. Chem. Phys, 2014, 14(10), 4895-4907. doi.10.5194/acp-144895-2014.

Faridi, S., Shamsipour, M., Krzyzanowski, M., Künzli, N., Amini, H., Azimi, F., Malkawi, M., Momeniha, F., Gholampour, A., Hassanvand, M. S., Naddafi, K., 2018. Long-term trends and health impact of $\mathrm{PM}_{2.5}$ and $\mathrm{O}_{3}$ in Tehran, Iran, 2006-2015. Environ. Int, 114, 37-49. doi.org/10.1016/j.envint.2018.02.026.

Han, L., Zhou, W., Li, W., Li, L., 2014. Impact of urbanization level on urban air quality: a case of fine particles $\left(\mathrm{PM}_{2.5}\right)$ in Chinese cities. Environ. Pollut, 194, 163-170. doi.org/10.1016/j.envpol.2014.07.022.

Han, L., Zhou, W., Li, W., 2015. City as a major source area of fine particulate $\left(\mathrm{PM}_{2.5}\right)$ in China. Environ. Pollut, 206, 183-187. doi.org/10.1016/j.envpol.2015.06.038.

Justice, C., Gutman, G., Vadrevu, K. P., 2015. NASA land cover and land use change (LCLUC): an interdisciplinary research program, J. Environ. Manage, 148C, 4-9. doi.org/10.1016/j.jenvman.2014.12.004.

Kendall, M. G., 1948. Rank Correlation Methods, Charles Griffin, London, 202.

Kumar, P., Gulia, S., Harrison, R. M., Khare M., 2017. The influence of odd-even car trial on fine and coarse particles in Delhi. Environ. Pollut, 225, 20-30. doi.org/10.1016/j.envpol.2017.03.017.

Li, J., Huang, X., 2018. Impact of land-cover layout on particulate matter 2.5 in urban areas of China, Int. J. Digit Earth, 1-13. doi.org/10.1080/17538947.2018.1530310.

Mann, H. B., 1945. Nonparametric tests against trend. Econometrica: Journal of the Econometric Society, 13, 245-259.

Plummer, S., Lecomte, P., Doherty, M., 2017. The ESA climate change initiative (CCI): A European contribution to the generation of the global climate observing system. Remote Sens of Environ, 203, 2-8. doi.org/10.1016/j.rse.2017.07.014.

Saikawa, E., Trail, M., Zhong, M., Wu, Q., Young, C. L., Janssens-Maenhout, G., Klimont, Z., Wagner, F., Kurokawa, J., Nagpure, A. S., Gurjar, B. R., 2017. Uncertainties in emissions estimates of greenhouse gases and air pollutants in India and their impacts on regional air quality, Environ. Res. Lett, 12(6), 065002. doi.org/10.1088/1748-9326/aa6cb4.

Saikawa, E., Panday, A., Kang, S., Gautam, R., Zusman, E., Cong, Z., Somanathan, E., Adhikary, B., 2019. Air Pollution in the Hindu Kush Himalaya, Springer, Cham, 339-387. doi.org/10.1007/978-3-319-92288-1_10.

Sahu, S. K., Ohara, T., Beig, G., 2017. The role of coal technology in redefining India's climate change agents and other pollutants. Environ. Res. Lett, 12(10), 105006. Environ. Res. Lett. doi.org/10.1088/1748-9326/aa814a. 
Sen, P. K., 1968. Estimates of the regression coeffcient based on Kendall's tau. J. Am. Stat. Assoc, 63(324), 1379-1389.

Sharma, M., Dikshit, O., 2016. Comprehensive Study on Air Pollution and Green House Gases (GHGs) in Delhi, http://delhi.gov.in/DoIT/Environment/PDFs/Final_Report.pdf.

Shi, Y., Matsunaga, T., Yamaguchi, Y., Li, Z., Gu, X., Chen, X., 2017. Long-term trends and spatial patterns of satelliteretrieved $\mathrm{PM}_{2.5}$ concentrations in South and Southeast Asia from 1999 to 2014, Sci. Total Environ, 615, 177-186. doi.org/10.1016/j.scitotenv.2017.09.241.

United Nations, 2019. World Urbanization Prospects: The 2018 Revision, https://population.un.org/wup/.

van Donkelaar, A., Martin, R.V., Brauer, M., Hsu, N.C., Kahn, R.A., Levy, R. C., Lyapustin, A., Sayer, A. M., Winker, D. M., 2016. Global estimates of fine particulate matter using a combined geophysical-statistical method with information from satellites, models, and monitors. Environ. Sci. Technol, 50, 3762-3772. doi.org/10.1021/acs.est.5b05833.

Vadrevu, K., Ohara, T., Justice, C., 2017. Land cover, land use changes and air pollution in Asia: a synthesis. Environ. Res. Lett, 12(12), 120201. Environ. Res. Lett. doi.org/10.1088/17489326/aa9c5d.

Wang, Q., Kwan, M. P., Zhou, K., Fan J., Wang Y., Zhan D., 2019. The impacts of urbanization on fine particulate matter ( $\mathrm{PM}_{2.5}$ ) concentrations: Empirical evidence from 135 countries worldwide, Environ. Pollut, 247, 989-998. doi.org/10.1016/j.envpol.2019.01.086.

Wang, Q., Tang, J., Zeng, J., Qu, Y., Zhang, Q., Shui, W., Wang, W., Yi, L., Leng, S., 2018. Spatial-temporal evolution of vegetation evapotranspiration in Hebei Province, China. J. Integr. Agric, 17(9), 2107-2117. doi.10.1016/S2095 3119(17)61900-2.

World Health Organization (WHO), 2006. WHO air quality guidelines for particulate matter, ozone, nitrogen dioxide and sulfur dioxide. Global update 2005. https://apps.who.int/iris/bitstream/handle/10665/69477/WHO_S DE_PHE_OEH_06.02_eng.pdf;jsessionid=CA948F2F53F9F06 1DAC6A7E25D7640E9? sequence=1.

World Health Organization (WHO). 2016. Urban Ambient Air Pollution Database 2016, https://www.who.int/airpollution/data/cities-2016/en/. 